\title{
Slag aggregates for railway track bed layers: monitoring and maintenance
}

\author{
M. Morata, C. Saborido \& V. Fontserè \\ Knowledge Management and R\&D Department, COMSA, Spain
}

\begin{abstract}
The use of aggregates with high abrasion resistance is key to guaranteeing a good track performance during time. However, obtaining these high-quality aggregates is not always feasible at a reasonable cost. Because of this, the creation of new alternatives with lower life cycle costs and lower environmental impact, such as SFS-Rail (steel furnace slag-rail), is fundamental for the economic and environmental sustainability of the railway infrastructure. SFS-Rail is made of recycled aggregates from electric arc furnace slag aimed to be used in subgrade and subballast layers and that offers excellent physical and mechanical properties.

In this paper, a worldwide review of the state-of-the-art experiences and legislation in using ferrous slag in railway applications is carried out. Next, an introduction of SFS-Rail and their main benefits in terms of track performance and environmental sustainability is made based on both laboratory tests and a life cycle assessment (LCA). Results from laboratory tests are compared to existing European norms regulating the use of aggregates in track bed layers to prove their suitability. The field tests undergone under the LIFE+ GAIN project in a mixed line (passenger and freight) of the Spanish infrastructure manager (ADIF) network are described. The extensive monitoring equipment to monitor SFS-Rail effect on track performance and the main results of the monitoring activities are shown, demonstrating the suitability of SFS-Rail in track bed layers and its contribution towards an enhanced abrasion resistance, track stability and durability, reducing the need of maintenance operations.
\end{abstract}

Keywords: slag, aggregate, railway, foundation, track bed.

\section{Introduction}

Track bed layers, which usually refer to ballast, subballast and subgrade layers, play a key role in track behaviour with respect to track support stiffness, 
maintenance of track geometry and drainage, among others. It is well-known that many problems related to track geometry come from a deficient condition of track bed layers. Therefore, if resilience and stability of railway infrastructure are sought, high quality aggregates for track bed layers should be employed.

Traditionally, materials employed in track bed and form layers are natural aggregates that derive from quarries. New challenges have arisen provided that high quality aggregates are a natural resource and they have started to be scarce and not always available. As a result, in some specific locations and projects, long transport routes must be done in order to get the right material, which results in an increase of not only cost, but of the environmental burdens associated to track construction. This occurs in a context where European Commission (EC) policies are increasingly stringent in environmental issues, whereas they encourage ever more sustainable, durable and cost-efficient solutions. For these reasons, the appearance of a new recycled material with enhanced mechanical properties seems to align perfectly with the future development of track infrastructure, where materials with best life cycle cost (LCC) and best LCA will prevail.

Within the framework of the GAIN project (funded by EC LIFE+ programme), a new recycled aggregate (SFS-Rail) has been developed not only to fulfil all the technical requirements of national and European norms regulating their employment in track bed and form layers, but to go beyond them and offer excellent mechanical properties. These aggregates are obtained by the valorisation of (black) electric arc furnace slag (EAFS).

In this paper, the state-of-the-art experience and legislation regarding furnace slag as aggregate in railways is introduced. Then the mechanical, physical, chemical and environmental characterisation of SFS-Rail is presented, including an LCA. Finally, the field test implementation in working conditions is described together with the monitoring activities undertaken and the main results, validating SFS-Rail as an alternative solution for railway track bed layers.

\section{State-of-the-art experience and legislation regarding furnace slag as aggregate in railways}

The SFS generated in Europe is mainly applied for road construction (48\%) while a $13 \%$ is sent to landfills. The use of ferrous slag in railway applications is not as common as in road construction and the only experiences found were in USA, Brazil, Canada and India. According to [1], in the USA in 1975 railroad ballast was the second most important application of Blast Furnace Slag (BFS), with 3.66 million tons (18\%), and the third most important of SFS, with 0.56 million tons $(8.4 \%)$. However, road base was by far the most common application for both types of slag. According to the data of the latest Mineral Yearbook published by the U.S. Geological Survey, in 2011 less than $6.6 \%$ of BFS was used for railroad ballast application, while road construction consumes around the $40 \%$. In Canada, specific norms regulate the use of slag in railway applications, namely the Canadian national railways (CNR) Specification 12-22, Slag ballast. On the other hand, in Brazil there is a process of standardisation of the steel slag underway at the Brazilian association for technical standards (ABNT) for its use as railway 
ballast. In what regards to India, some tests have been undertaken to prove that steel slag fulfils the specifications required by the Indian Railways (IR) for railway ballast [2]. In contrast, there has not been found any evidence of railroad application of SFS in Europe or relevant research on this topic. As a result, the GAIN project aims at developing a new type of aggregates coming from EAFS that complies with the European norms so that they can be used similarly as in other industrialised countries.

Slag aggregates must comply with the existing norms regulating the use of aggregates in subgrade and subballast layers. At this moment, it can only be found a specific railway standard, at a European level, for ballast aggregates (EN 13450:2013) but not for the subballast or subgrade aggregates. There is a more general standard regulating the aggregates for civil applications (EN 13242:2013), which includes some specifications regarding the use of steel slag as aggregate for foundation layers. The standard states that slag aggregates can be considered stable if the expansion (according to EN 1744-1) does not exceed the maximum values, depending on the application or its final use.

Although there is not a common norm for Europe, in each country, the railway administration has developed its own regulations establishing the specifications that aggregates must accomplish to be used in track bed layers. In table 1, the different criteria among countries can be seen.

Table 1: National specifications for earthworks and track bed layers (adapted from $[3,4]$.)

\begin{tabular}{|c|c|c|c|c|c|}
\hline Organisation & Country & $\begin{array}{l}D \max \\
(\mathrm{mm})\end{array}$ & $\begin{array}{l}\text { Fines } \\
(\%)\end{array}$ & $\begin{array}{c}\text { Fracture } \\
\text { faces }\end{array}$ & $\begin{array}{c}\text { Los } \\
\text { Angeles }\end{array}$ \\
\hline \multirow{2}{*}{ Deutsche Bahn } & \multirow{2}{*}{ Germany } & 56 & $<5-7$ & - & - \\
\hline & & 63 & $<5-7$ & - & - \\
\hline Infrabel & Belgium & 40 & - & - & - \\
\hline ZSR & Slovakia & 63 & $5-14$ & - & - \\
\hline SCNF & France & 31.5 & $4-8$ & 100 & - \\
\hline \multirow{2}{*}{ Network Rail } & \multirow{2}{*}{ Great Britain } & \multirow{2}{*}{2.36} & $<10$ & \multirow{2}{*}{-} & - \\
\hline & & & $>4$ & & - \\
\hline \multirow{2}{*}{ RFI } & \multirow{2}{*}{ Italy } & 25.4 & $6-10$ & $>67$ & $<30$ \\
\hline & & 40 & $2-7$ & - & - \\
\hline $\mathrm{CD}$ & Czech Republic & 32 & $<5$ & $<50$ & - \\
\hline \multirow{2}{*}{ Banverket } & \multirow{2}{*}{ Sweden } & 150 & \multirow{2}{*}{$0-6$} & 100 & - \\
\hline & & 150 & & 100 & $<25$ \\
\hline ADIF & Spain & 40 & $3-9$ & 100 & $<28$ \\
\hline
\end{tabular}

On the other hand, slag aggregates should comply with additional norms compared to aggregates obtained from quarries, given that in many countries they are still treated as waste and specific tests must be carried out in order to allow them being recycled and used as a product. 
Classification of slag by European legislation has evolved during the last years as a result of 25 years of discussion on this issue. How slag aggregates are classified according to EU legislation - waste, product or by-product - has a direct effect on the strictness of the requirements they have to fulfil. According to the revised Waste Framework Directive 2008/98/EC [5], some types of slag can be considered as by-product or even as a product. At a national level, some of the slag types are recognised as non-waste, products or by-products (e.g. in Belgium, Finland, Germany, Austria and the United Kingdom) but still have a waste status in some other countries. Steel slags, in particular, are often considered as a waste, especially in the liquid state and before treatment [6].

There are several countries in Europe such as Germany that have developed specific standards for regulating the use of steel slag as subballast and other civil applications. Nevertheless, there is a lack of these norms in some other European countries (e.g. Spain, Portugal, among others) and, therefore, much work is still needed to address the development of these regulations. The development of new solutions based on ferrous slag such as SFS-Rail contributes to a high extent towards the standardisation and regulation on this matter.

\section{SFS-Rail: EAFS aggregates for subballast and subgrade layers}

SFS-Rail refers to the commercial brand of the new aggregates made of EAFS to be used in railway applications, namely for sub-ballast and subgrade foundation layers. It can be produced with different granulometries (see figure 1). Its physical, mechanical, chemical and environmental features have been assessed by an extensive campaign of laboratory tests and a LCA, whose main considerations and results are described below.

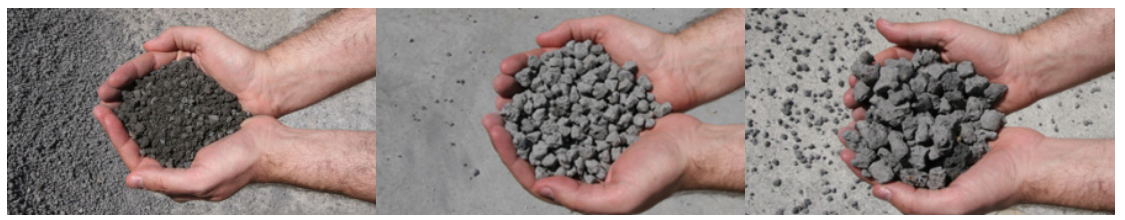

Figure 1: Different granulometries of SFS-Rail.

\subsection{Physical and mechanical characterisation of SFS-Rail}

Tests to determine the physical properties of SFS-Rail have reported a bulk density of $3.56 \mathrm{~kg} / \mathrm{m}^{3}$, water absorption of $1.6 \%$ a fine content of $4.20 \%$ and a high percentage of voids space. The tests have been carried out according to the Spanish standards UNE-EN 1097-6 for density, water absorption and voids space and UNE-EN 933-1 for the determination of the fine content. Other physical properties assessed are the fracture faces and the expansiveness index. SFS-Rail offers 100\% of fracture faces, which guarantees a good interlocking between particles, while 
the accelerated expansiveness according to UNE-EN 1744-1 has proved to be $0.3 \%$ after 168 hours.

Regarding the mechanical characterisation of SFS-Rail, the Los Angeles (LA) test has been carried out in a first instance, provided that it measures the abrasion resistance of aggregates, which is one of the most relevant parameters for aggregates in railway applications. The tests give a LA value of 15-20, comparing favourably with good hard rocks and most standards, which require a maximum LA of 30 (e.g. the maximum value established by the Spanish norm is 28 [7]). Note that the LA value for aggregates to be used in concrete applications is considerably higher (i.e. less demanding) and goes up to 50, as stated by the Spanish norm UNE-EN 12620.

The high performance of SFS-Rail against abrasion is confirmed by the results of the Micro-Deval (MD) test and the polished stone value (PSV). Thus, SFS-Rail showed a MD below 20, in compliance with the Spanish norm [7], while it offers a PSV between 57 and 65, which is within the aggregates "High Performance" category, whereas it is difficult and expensive to obtain a rock with such characteristics. Finally, tests to assess the California bearing ratio (CBR) index were carried out according to UNE 103502. In all cases, CBR results were above 100 , which is considerably higher than that of conventional aggregates.

It has to be stressed out that all the above values are in line with the results reported by scientific literature regarding steel slag characterization, such as [8], which reports a bulk density of $3.5 \mathrm{~kg} / \mathrm{m}^{3}$ and a PSV of 61 , among other parameters; and [9], which reports a LA value of $17 \%$ and a water absorption of $0.8 \%$. Indeed, the "European Association representing metallurgical slag producers and processors" (EUROSLAG) states that the chemical, mineralogical and physical properties of steel slag are similar to those of natural rocks, with enhanced performance due to their high density $\left(3.6 \mathrm{~kg} / \mathrm{m}^{3}\right)$, low impact value (17\%), high compressive strength $\left(200 \mathrm{~N} / \mathrm{mm}^{2}\right)$, good polishing performance (PSV of 57) and high freeze/thaw resistance [10].

Note that SFS-Rail has a lack of fine material and, in order to comply with the granulometry curve for the subballast layer, as defined in [7], it must be mixed with natural aggregates in a proportion of $75 \%$ SFS-Rail and $25 \%$ natural aggregates. The LCA and the field tests, which are detailed in the following sections, have been carried out with this proportion.

\subsection{Chemical and environmental characterisation of SFS-Rail}

Several laboratory tests have been carried out to determine the chemical composition of SFS-Rail. They have proved to be highly resistant to change by wetting and drying, as well as to freezing and thawing, to extreme changes in temperature and to chemical attacks. Besides, the absence of organic matter prevents the growth of unwanted vegetation.

A special focus has been put on the leaching tests, whose main objective has been to quantify the mobility of the chemical species (pollutant or not) contained in the SFS-Rail aggregates. The leaching tests have been undertaken according to EN 12457-4, where SFS-Rail is submerged into water and its release of constituents is monitored. 
The analysis criteria to classify SFS-Rail as inert or hazardous consist of a list of maximum concentration values for each chemical substance, which may vary depending on the standard applied. In table 2, the thresholds for the Decree $32 / 2009$ [11] of Catalonia are shown together with the results of the leaching tests performed on SFS-Rail, showing that none of the thresholds were surpassed.

Table 2: Results of the leaching tests and threshold values according to the Decree 32/2009.

\begin{tabular}{|ccc|}
\hline Parameters & $\begin{array}{c}\text { Results of the leaching tests } \\
\text { performed on SFS-Rail }\end{array}$ & $\begin{array}{c}\text { Threshold by decree } \\
\mathbf{3 2 / 2 0 0 9}(\mathbf{m g} / \mathbf{k g})\end{array}$ \\
\hline Arsenic & 0.00 & 0.5 \\
\hline Barium & 3.44 & 20 \\
\hline Cadmium & $<0.01$ & 0.04 \\
\hline Chlorides & 52.54 & 800 \\
\hline Chromium & 0.20 & 0.5 \\
\hline Copper & 0.21 & 2 \\
\hline Fluorine & 0.01 & 18 \\
\hline Mercury & 0.00 & 0.01 \\
\hline Molybdenum & 0.14 & 0.5 \\
\hline Nickel & 0.02 & 0.4 \\
\hline Lead & 0.14 & 0.2 \\
\hline Antimony & 0.03 & 0.06 \\
\hline Selenium & $<0.05$ & 0.1 \\
\hline Sulphurs & 281.74 & 1000 \\
\hline Zinc & 3.36 & 4 \\
\hline
\end{tabular}

Based on the above mentioned results, one can state that SFS-Rail offers high resistance to wear and abrasion and an increased lateral stability mainly due to: (a) a better interlocking of particles as a consequence of the sharp corners and rough, pitted surfaces; and (b) to the heavier weight of aggregates. As a result, tracks using SFS-Rail are not only more durable but also more resistant to lateral track movements in tight curves. Besides, the higher percentage of voids space provides SFS-Rail with a higher drainage capacity than conventional aggregates. The above statements are supported by other relevant research on slag material applications in the railway field, such as [12], which highlights the advantages of steel slag when used as ballast.

\subsection{LCA of SFS-Rail}

Among the tools available to monitor environmental performance, the LCA provides a holistic approach by considering the potential impacts from all stages of manufacture, product use and end-of-life stages. Thus, the LCA is a tool for quantifying the environmental performance of products taking into account the complete life cycle, starting from the production of raw materials to the final disposal of the products, including the material recycling if needed $[13,14]$. 
Although the LCA is a topic of growing interest to the industry, it has not been much considered in the construction industry and even less in the railroad construction industry. Some of the reasons are that there is not a huge volume of new railway lines being constructed and that the environmental impacts associated to the railway construction are usually analysed under the perspective of the more common road construction. Nevertheless, there are many aspects of the construction, monitoring and maintenance of railway infrastructures that need to be addressed under an environmental perspective, for which a LCA gives much insight. Indeed, the LCA results will be of a high value to convince Railway Infrastructure Managers and Public Administration to use SFS-Rail in their rail networks due to its lower impact on the environment.

\subsubsection{Goal and scope definition}

The primary goal of the LCA carried out is the comparison of environmental aspects between SFS-Rail and the conventional aggregates employed in the subballast and subgrade layers in accordance with ISO 14040:2006 and ISO 14044:2006 standards [15, 16]. For the sake of simplicity, only the results regarding the subballast comparison have been included in this report.

The functional unit has been the extraction of natural aggregates and the production of SFS-Rail and its transport to the construction site (cradle-to-gate) for $1 \mathrm{~km}$ of a single railway track with a subballast layer $8.5 \mathrm{~m}$ wide and $25 \mathrm{~cm}$ thick. The database used for this LCA has been the GaBi Professional database 2014. The methodology adopted has been the so-called CML 2001 method [17].

\subsubsection{LCI}

The data that have been used for this study can be classified in three groups:

- Primary data provided by the steel slag valorisation plant of ADECGLOBAL.

- Primary data from similar studies or analyses [18, 19].

- Primary data from GaBi 6 Professional database.

\subsubsection{LCIA}

The following LCIA categories have been analysed:

- Global warming potential (GWP), which causes climate changes, including increased global average temperatures and sudden regional climatic changes.

- Acidification potential (AP), which is caused by acids and compounds which can be converted into acids, eventually decreasing soil's $\mathrm{pH}$.

- Eutrophication potential (EP), also called nutrient enrichment, which it affects the function and structures of the ecosystems by exerting toxic effects on the organisms that live in them.

- Human toxicity potential (HTP), which covers a number of different effects (acute toxicity, irritation effects, allergic effects, etc.) and exposure via different media (air, water and soil) related with human health.

The combination of $75 \%$ SFS-Rail with $25 \%$ natural aggregate reported a reduction in GWP by a $45 \%$, AP by a $44 \%$, EP by $9 \%$ and HP by $193 \%$ with respect to the natural aggregates scenario. 


\subsubsection{Interpretation of results}

As a conclusion of this analysis one can state that, beyond its technical improvements, SFS-Rail is a better product for the environment than the conventional solution employing natural aggregates/soil in the subballast and subgrade layers of railway lines. The use of SFS-Rail is even better if the location of the valorisation plant is close to the construction site, since the environmental impact associated to road transport diminishes, which is the major contributor to GWP, EP and AP. Besides, SFS-Rail allows a reduction of the thickness of the subballast and subgrade layers of railway tracks, hence reducing the demand of natural aggregates and transport needs and, consequently, decreasing even further their associated environmental impacts.

\section{Demonstration field tests: monitoring results}

Although the laboratory tests and the LCA have shown that SFS-Rail has excellent mechanical, physical, chemical and environmental properties, two field tests have been constructed in order to demonstrate and validate its performance in real conditions. The first field test has been constructed in a freight line in El Musel harbour in Gijón, Spain, in a line owned by the harbour authority. The second one has been constructed in a mixed line (i.e. passengers and freight) owned by ADIF in Castellbisbal, near Barcelona, Spain. The description that follows refers to the latter, as ADIF is the main Spanish IM and the field test carried out in their network has a major demonstration and replicability potential.

Three sections of $50 \mathrm{~m}$ each have been constructed: i) a $50 \mathrm{~m}$ long section with the subballast layer made of SFS-Rail and the subgrade layer with the existing conventional aggregates; ii) a $50 \mathrm{~m}$ long section with both the subballast and subgrade layers made of SFS-Rail; and iii) a $50 \mathrm{~m}$ long section with the existing conventional aggregates (control section), which has been divided in two $25 \mathrm{~m}$ long stretches at both ends of the field tests.

The field tests have been designed so as to assess the performance of the different track sections in terms of the following three parameters:

- Track settlement and geometry, as a measure of the track alignment, thickness of the compacted layers, strength, density (compaction) and moisture.

- Subballast and subgrade stress under traffic, as a measure of the capability of distributing the stress towards the platform, which relates to the track strength (bearing capacity).

- Rail deflection under traffic, as a measure of the track stiffness (soil modulus) and its elastic deformation.

Track settlement and geometry are monitored by periodical topographic surveys (every two months). To monitor the settlement of each layer, 12 tubes have been designed ad hoc and positioned on the subballast and subgrade layers (see figure 2(a)) so that their head can be read from a topographic station placed outside the track. The subballast and subgrade stress under traffic is monitored through vibrating wire pressure cells, which have been installed under the subballast and subgrade layers made of SFS-Rail (see figure 2(b)). After the extension and compaction of the upper layers, the track assembly (see figure 3 ) 
and ballast profiling and tamping, the field tests have been opened to traffic. Rail deflection can then be measured by instantaneous topographic surveys of rail web references during passage of trains (see figure 4).

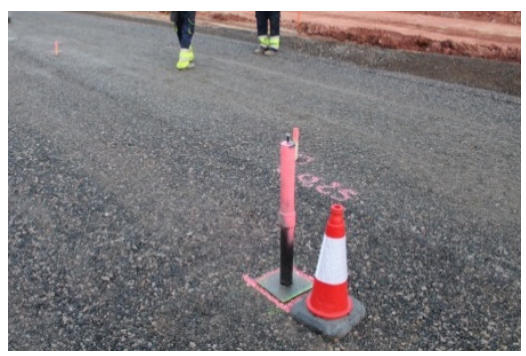

(a)

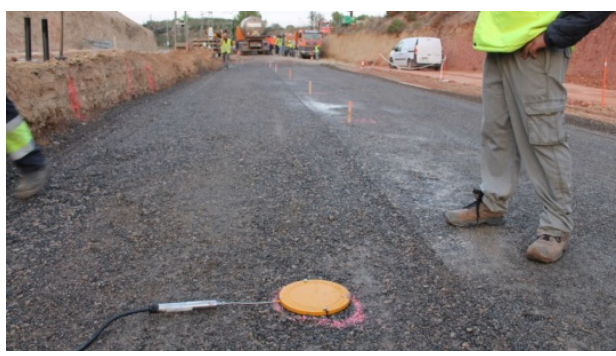

(b)

Figure 2: (a) Tube to monitor the settlement of the underlying subgrade layer made of SFS-Rail. (b) Installation of a vibrating wire pressure cell to monitor the stress of the subballast layer made of SFS-Rail.

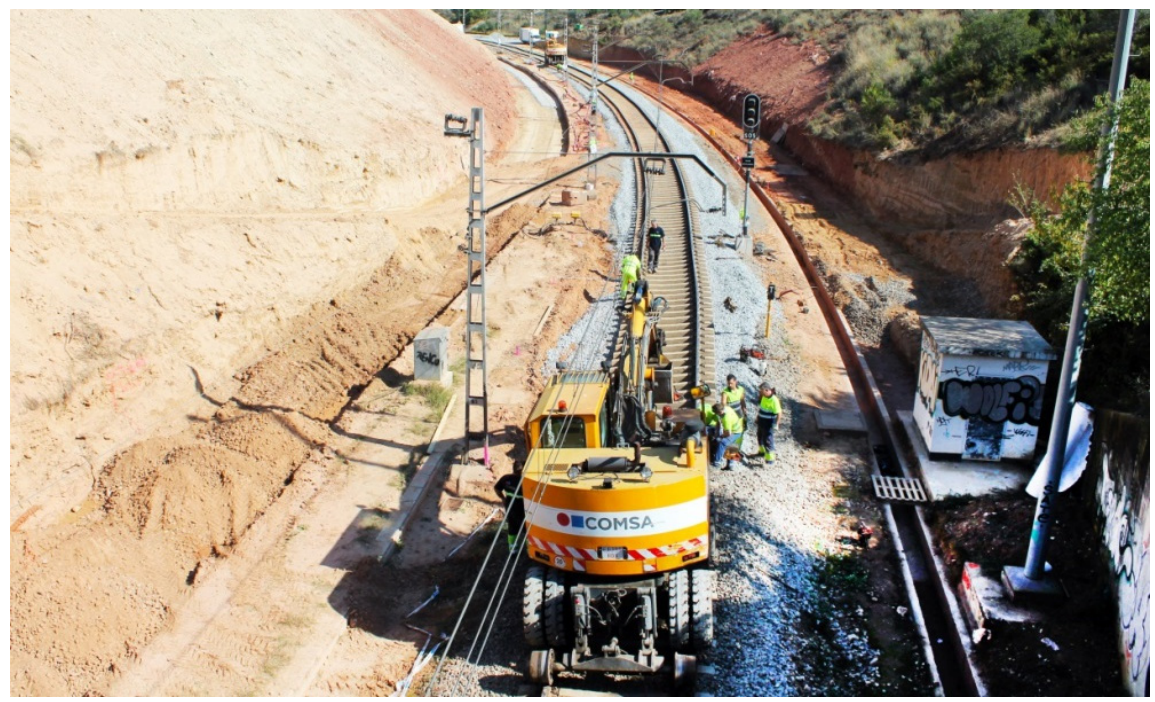

Figure 3: Track assembly.

At the moment, two readings have taken place in the field tests besides the initial survey, according to the monitoring plan. The stress measured on the subballast and subgrade layers made of SFS-Rail is presented in table 3, showing admissible values (under $0.15 \mathrm{MPa}$ ) while evincing a reduction on the stress of the subgrade compared to the subballast layer, hence proving SFS-Rail bearing capacity and its capability to distribute stress. Stresses are scaled up in the 
second reading due to a higher axle load of the commuter unit circulating at the time of the measurements. Rail deflection under the passage of a commuter unit is presented in table 4 , indicating a compaction of the infrastructure with time while manifesting acceptable values (under $3 \mathrm{~mm}$ in the second reading) and a reduction in deflection when SFS-Rail is used, which demonstrates the increase in soil modulus (track stiffness) with respect to conventional aggregates. Finally, results on track settlement are presented in figure 5, showing an overall progressive but restrained settlement during time. This is more pronounced where SFS-Rail is employed in both layers, since the conventional aggregates have not been replaced and they are already compacted.

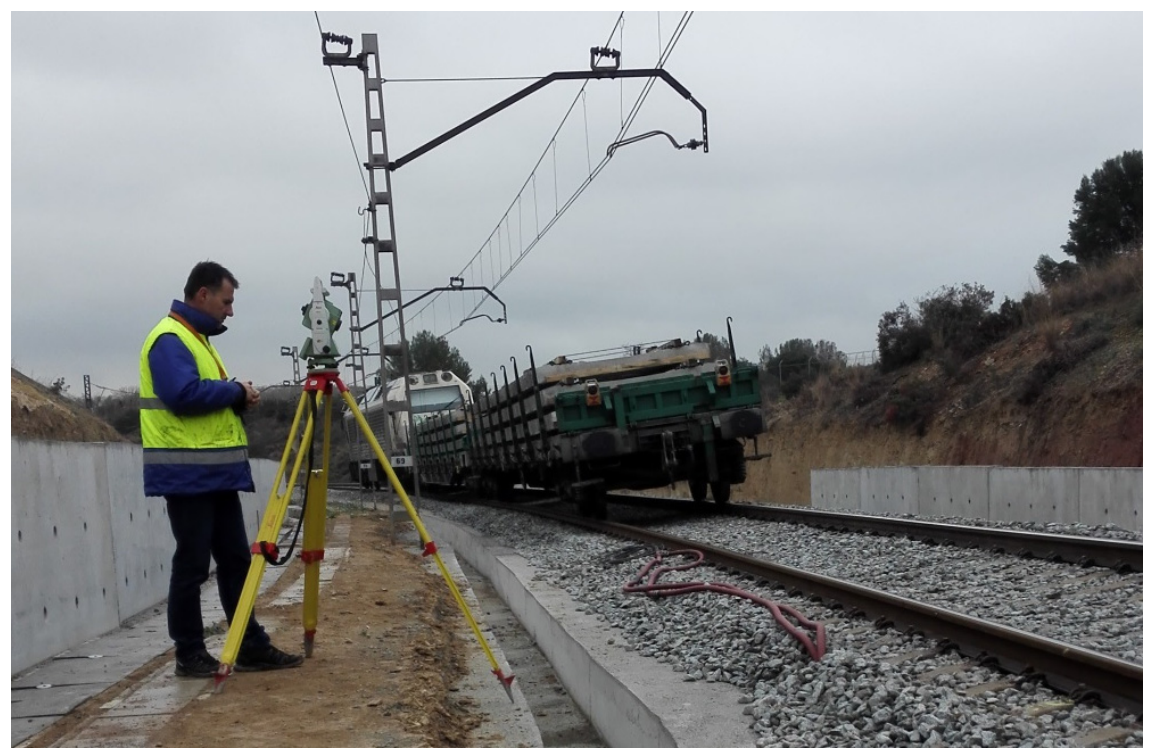

Figure 4: Monitoring of rail deflection under the passage of a train.

Table 3: Stress measured on the subballast and subgrade layers made of SFSRail under the passage of a commuter unit.

\begin{tabular}{|ccc|}
\hline & 1st reading & 2nd reading \\
\hline Stress (MPa) on SFS-Rail subballast layer. & 0.077 & 0.104 \\
\hline Stress (MPa) on SFS-Rail subgrade layer. & 0.032 & 0.042 \\
\hline
\end{tabular}

Table 4: Rail deflection (in $\mathrm{mm}$ ) measured under the passage of a commuter unit.

\begin{tabular}{|ccc|}
\hline & 1st reading & 2nd reading \\
\hline Subballast and subgrade layers with SFS-Rail & 1.2 & 1.0 \\
\hline $\begin{array}{c}\text { Subballast layer made of SFS-Rail and } \\
\text { subgrade layer with conventional aggregates }\end{array}$ & 2.7 & 1.3 \\
\hline Control section (conventional aggregates) & 4.5 & 3.0 \\
\hline
\end{tabular}




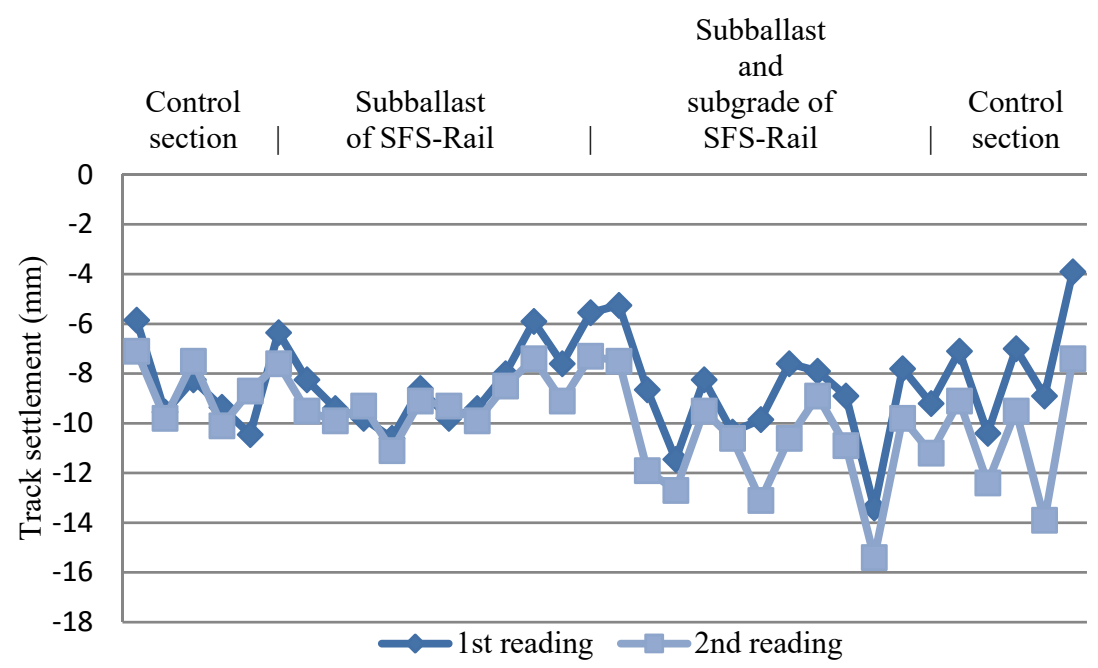

Figure 5: Overall track settlement with respect to the initial survey.

\section{Conclusions}

In this paper, the main results of the SFS-Rail characterisation by laboratory tests, the LCA and field test implementation and monitoring have been presented.

It has been proved that SFS-Rail emerges as a high quality aggregate offering an abrasion resistance and hardness considerably higher than most of natural aggregates commonly employed in railway foundations. Its suitability in track bed layers has been validated through the field tests demonstration, which has evinced its contribution towards improved track stiffness, track stability, bearing capacity (strength) and durability, hence enabling a reduction of maintenance needs and the frequency of track renewal operations.

The enhanced performance of SFS-Rail in track bed layers jointly with a competitive price, the reduction of maintenance costs and a much reduced environmental impact (it avoids the environmental impact of quarries while reusing an abundant industrial waste) makes it a very attractive alternative to natural aggregates.

\section{References}

[1] Van Oss, K. G., Slag - Iron and Steel, U.S. Geological Survey Minerals Yearbook, 2000.

[2] Pumar, T., Utilisation of Steel Melting Slag to Generate Wealth from Waste, Proceedings of the International Conference on Environmental, Management in Metallurgical Industries, 187-193, 2000. 
[3] Union Internationale de Chemins de Fer, Earthworks and Track Bed Construction for Railway Lines, Leaflet 719, 2008.

[4] López Pita, A., Infraestructuras Ferroviarias, Temas de Transporte y Territorio, Ediciones Universitat Politècnica de Catalunya, 2006.

[5] Waste Framework Directive 2008/98/EC

[6] EUROSLAG, EUROFER, Position paper on the status of ferrous slag complying with the Waste Framework Directive and the REACH regulation, 2012.

[7] ORDEN FOM/1269/2006, de 17 de abril, por la que se aprueban los Capítulos: 6.-Balasto y 7.-Subbalasto del pliego de prescripciones técnicas generales de materiales ferroviarios (PF), 2006.

[8] Motz, H. \& Geiseler, J., Waste Management, 21 285-293, 2001.

[9] Qasrawi, H., The use of steel slag aggregate to enhance the mechanical properties of recycled aggregate concrete and retain the environment, Construction and Building Materials, 54 298-304, 2014.

[10] EUROSLAG, www.euroslag.com/products/

[11] Diari Oficial de la Generalitat de Catalunya, Decret 32/2009, de 24 de febrer, sobre la valorització d'escòries siderúrgiques, Núm. 5328 27.2.2009.

[12] National Slag Association, Steel Furnace Slag... and ideal railroad ballast, NSA 173-3, 2001.

[13] Scientific Applications International Corporation (SAIC), Life Cycle Assessment: Principles and practice, 2006.

[14] World Steel Association, Methodology Report, Life cycle inventory study for steel products, 2011.

[15] BS EN ISO 14040:2006, Environmental management. Life cycle assessment. Principles and framework, 2006.

[16] BS EN ISO 14044:2006, Environmental management. Life cycle assessment. Requirements and guidelines, 2006.

[17] Guinée, J. B., Gorrée, M., Heijungs, R., Huppes, G., Kleijn, R., Koning, A. de, Oers, L. van Wegener, Sleeswijk, A., Suh, S., Udo de Haes, H. A., Bruijn, H. de, Duin, R. \& van Huijbregts, M. A. J., Handbook on life cycle assessment. Operational guide to the ISO standards. I: LCA in perspective. IIa: Guide. IIb: Operational annex. III: Scientific background. Kluwer Academic Publishers, ISBN 1-4020-0228-9, Dordrecht, 692, 2002.

[18] Korre, A. \& Durucan, S., Life Cycle Assessment of Aggregates, EVA 025 project, Imperial College London, 2009.

[19] SARMa, Scheme for Life Cycle Inventory data collection, 2011. 